\title{
Process Evaluation of a Peer-Driven, HIV Stigma Reduction and HIV Testing Intervention in Latino and African American Churches
}

\author{
Karen R. Flórez, ${ }^{1,2}$ Denise D. Payán, ${ }^{2,3}$ Kathryn P. Derose, Frances M. Aunon, and Laura M. Bogart ${ }^{2}$
}

\begin{abstract}
Purpose: Faith-based organizations may be effective in addressing HIV-related disparities, but few interventions have been implemented across diverse churches. The Facilitating Awareness to Increase Testing for HIV (FAITH) intervention harnessed peer leadership to decrease HIV stigma and promote HIV testing in African American and Latino congregations. A pilot study found more consistent effects among Latino congregations. This process evaluation evaluates implementation of FAITH to better understand the pilot study's findings.

Methods: Data sources included HIV education and peer leader workshop evaluation forms, participant views of the community's perspective of HIV, and peer leader follow-up interviews. Data were triangulated with systematic observation notes and analyzed using process-related themes of recruitment, reach, context, implementation, dose-delivered, and fidelity.

Results: At the Latino churches (compared to the African American church), facilitators spent more time addressing community-based misconceptions about HIV. The peer leader model was well received, especially among Latino participants, and most said that after the workshop they felt comfortable speaking with others about HIV-related topics. Latino peer leaders reported speaking with up to 20 people within their social networks (particularly with family members); African Americans reported up to 4. Implementation challenges at the African American church may have contributed to the limited intervention effects. Nevertheless, we found the peer motivator model feasible and acceptable across diverse faith settings.

Conclusion: Peer-based models within faith settings are promising for addressing HIV. However, differences among groups in HIV knowledge, social network characteristics and norms, and church preferences may influence overall effectiveness.
\end{abstract}

Keywords: HIV/AIDS; process evaluation; African Americans; Latinos

\section{Introduction}

Latinos and African Americans have disproportionately high HIV incidence, morbidity, and mortality rates and less access to HIV treatment and care services compared to other racial/ethnic groups in the United States. ${ }^{1}$ They are also disproportionately impacted by factors that increase HIV vulnerability, including poverty, limited healthcare access, discrimination, acculturation processes, higher community prevalence of other sexually transmitted infections, and detrimental HIV-related attitudes (e.g., homonegativity). ${ }^{2-6}$

Church-based interventions targeting HIV-related stigma may be an effective strategy to increase HIV

\footnotetext{
${ }^{1}$ CUNY Graduate School of Public Health and Health Policy, New York, New York. ${ }^{2}$ RAND Corporation, Santa Monica, California.

${ }^{3}$ UCLA Fielding School of Public Health, Los Angeles, California.

${ }^{4}$ Department of Psychology, University of Washington, Seattle, Washington.
}

*Address correspondence to: Karen R. Flórez, DrPH, MPH, CUNY Graduate School of Public Health and Health Policy, 55 West 125 th Street, New York, NY 10027, E-mail: karen.florez@sph.cuny.edu

(c) RAND Corporation 2017; Published by Mary Ann Liebert, Inc. This is an Open Access article distributed under the terms of the Creative Commons Attribution License, which permits unrestricted use, distribution, and reproduction in any medium, provided the original work is properly cited. 
education and screening among African American and Latino communities and reduce HIV-related disparities ${ }^{7}$ since churches have long been recognized as trusted sources in these communities and are important sources of social capital and information to individuals throughout the lifecourse. ${ }^{2,8,9}$

Most church-based HIV interventions have solely focused on African Americans despite the fact that Latinos also are disproportionately affected by HIV and exhibit high church attendance rates. ${ }^{10}$ Thus, little process evaluation research exists that explores implementation of church-based HIV interventions with Latinos and elucidates differences in implementation between these two disparity groups. Addressing this gap is particularly important given the increasing diversity in many urban settings. For example, in Los Angeles (the location of the present study), many disparity communities have shifted over the last 30 years from being predominantly African American to increasingly Latino. This diversification of the urban landscape requires interventions that can be implemented across diverse faith settings and with multiple disparity groups.

Several other process-related aspects of churchbased interventions are important, including a better understanding of individual participants' reactions to interventions and whether they share information with other congregants. One consistently noted advantage of church-based interventions is the naturally occurring social networks through which peer leaders can model behavior, influence attitudes, and share information. ${ }^{11}$ Indeed, several small pilot studies have shown that peer-led health interventions at churches can influence many health behaviors among congregants. ${ }^{12-14}$ However, very little is known about the feasibility and acceptability of a peer-led HIV intervention in a nonclinical setting ${ }^{15}$ or the lessons learned from implementing such a program across different racial/ethnic groups and religious denominations.

To fill this gap, we conducted a process evaluation of Facilitating Awareness to Increase Testing for HIV (FAITH), a multifaceted, congregation-based intervention piloted in a cluster randomized controlled trial with two African American churches and three Latino churches in Los Angeles County. The intervention was developed using community-based participatory research $(\mathrm{CBPR})^{16}$ through which public health and faith-based partners were involved in all phases of the research, including extensive formative research that identified key elements of successful HIV-related programs across different faith-based settings. ${ }^{17-22}$ Drawing from these findings and social psychological stigma reduction theories, ${ }^{23}$ we developed the multicomponent intervention. Results from our pilot study found that, at the church level, the intervention reduced HIV stigma and HIV mistrust among the Latino churches and increased HIV testing across the African American and Latino churches. ${ }^{24}$ Specifically, the Latino Catholic intervention church experienced a decrease between baseline and follow-up in both HIV stigma and HIV mistrust (effect size change $=-0.16$; 95\% confidence interval [CI] -0.25 to -0.06 for HIV stigma; -0.15 for HIV mistrust; $95 \%$ CI -0.24 to -0.05). Similarly, the Latino Pentecostal intervention church experienced a significant decrease in both outcomes between baseline and follow-up (effect size change $=-0.38$ for $\mathrm{HIV}$ stigma; $95 \% \mathrm{CI}-0.71$ to -0.05 ; -0.56 for HIV mistrust; $95 \%$ CI -0.86 to -0.27). For the African American Baptist intervention church, there were significant changes between baseline and follow-up in terms of HIV testing, but no significant change regarding HIV stigma or HIV mistrust. Taken together, these findings provide evidence that church-based interventions have the potential to reduce HIV-related disparities, but more information is needed to understand potential implementation differences across churches. Through in-depth process evaluation, we aimed to understand differences in implementation across the intervention churches that may account for the differences in effects.

A key component of FAITH involved HIV education and peer leader workshops. Here we assess implementation of these workshops through concepts of recruitment, reach, context, implementation, dose-delivered, and fidelity. ${ }^{25}$ Prior church-based intervention process evaluations have focused mainly on recruitment and reach. ${ }^{26}$ We evaluate a wider range of factors that likely influenced effectiveness. We also provide lessons learned from implementation to provide guidance for future church-based programming efforts that use peer leadership to address HIV. Given the sensitive nature of HIV in the church context and the fact that HIV is an understudied health condition in the church-based literature, ${ }^{2}$ this study fills an important gap in the literature by highlighting the issues involved in planning, implementing, and evaluating similar intervention efforts aimed at reducing HIV disparities among African Americans and Latinos. 


\section{Methods}

Our process evaluation framework incorporates constructs identified as important for evaluating implementation of health promotion interventions, ${ }^{27-29}$ and was applied to all intervention churches, which were selected from six churches matched on race/ethnicity, denomination, and congregation size in and around the city of Long Beach, California. More specifically, one pair of churches were selected from each of the following three types: medium African American Baptist, large Latino Roman Catholic, and small Latino Pentecostal. After reaching out to congregations with a formal written invitation, five churches agreed to participate in the pilot: two medium-sized (125-250 members) African American Baptist, two small (100 members) Latino Pentecostal, and one large (2000+ members) Latino Catholic church. Because these three denominations represent large segments of Latinos and African Americans and because we included congregations of various sizes (which has been shown to affect implementation of health programming), we felt confident that our study would yield important information about feasibility, acceptability, and potential impact to implement this type of intervention across diverse congregational settings. All study protocols were approved by the RAND Human Subjects Protection Committee.

\section{Intervention description}

Intervention components and development are described fully elsewhere ${ }^{30}$ and are summarized briefly here and in Figure 1. One component was the HIV sermon, in which a pastor or priest delivered a sermon or homily about HIV using their own preaching style and tradition, but focused on HIV and related stigmas in the community. A second component involved congregation-based HIV testing events conducted by health department counselors who administered a rapid oral fluid testing and counseling in a mobile clinic at the church. A third component involved implementing HIV education workshops to raise awareness about HIV-related stigma and the importance of HIV screening to reduce racial/ethnic disparities. A fourth component was the peer leader workshops designed to leverage the natural occurring social networks within the church to create "seeds" or peer motivators who could help decrease HIV-related stigma and increase HIV testing among congregants and community members. Indeed, this concept of "seeds" was inspired by respondent-driven sampling and shown to be an effective way of increasing use of HIV testing and preven- tion services among vulnerable Latino populations. ${ }^{31}$ Both set of workshops were led by a trained facilitator from the research team and an HIV educator and counselor from a local health department.

\section{Data sources}

Participant evaluation forms. Self-administered forms collected basic sociodemographic information and participants' ratings of various aspects of the workshops using a 3-point scale (e.g., how useful and appropriate for the church environment).

Observation forms. Trained research team observers assessed workshops' dynamics (e.g., level of engagement) systematically using targeted notes and checklists on level of interest, participation, and clarity of information provided using a 5-point Likert scale $(1=$ not at all to $5=$ all/nearly all). The peer leader observation form also assessed level of enthusiasm and comfort level using the same 5-point Likert scale.

Q\&A cards. Cards were completed by HIV educational workshop participants on (1) any information they had heard about HIV and how it is spread; and (2) what people in their community thought about people living with HIV (PLHIV). Cards were collected by facilitators and used to tailor comments on and prioritize key educational messages.

Peer leader follow-up interviews. Project staff conducted phone interviews several weeks after the peer leader workshops and asked specific questions about the number and type of people peer leaders spoke with about HIV, topics discussed (e.g., HIVrelated stigma), and experiences with their social network. Participants rated their level of comfort using a 4-point scale $(1=$ Very Comfortable to $4=$ Very Uncomfortable).

\section{Data analysis}

We used a mixed-method (quantitative/qualitative), web-based data analysis platform called Dedoose. ${ }^{32}$ All data were analyzed in the original language in which the data were gathered (English or Spanish).The initial qualitative coding tree utilized the process evaluation constructs (recruitment, reach, context, implementation, dose-delivered, and fidelity) and was applied independently by two coauthors to all data sources and discrepancies were resolved by consensus. Next, using the coded transcripts, research team members worked 


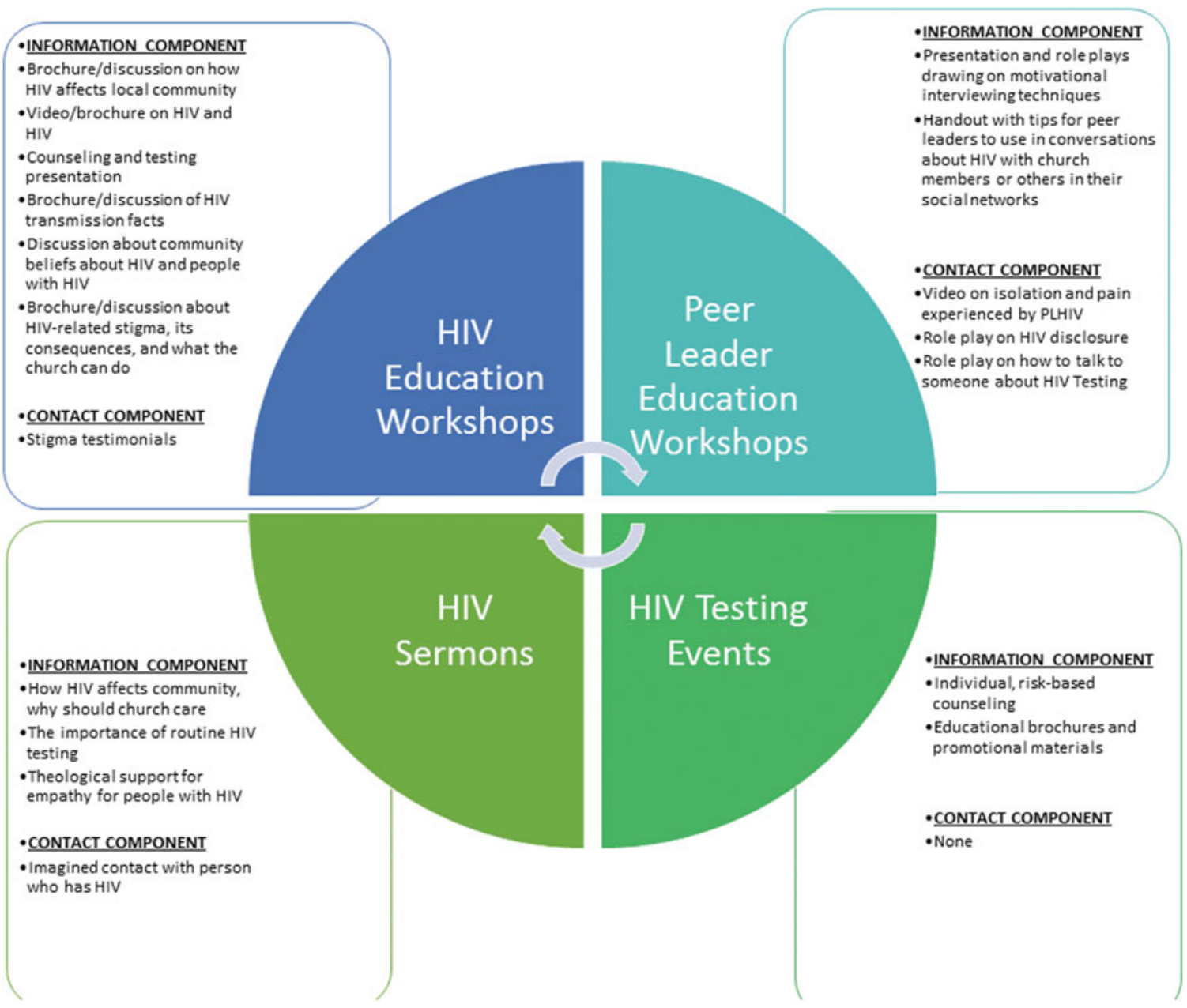

FIG. 1. Facilitating Awareness to Increase Testing for HIV (FAITH) components.

in pairs to maintain inter-rater reliability, confirm emergent themes related to process evaluation constructs (e.g., implementation, context), and resolve any other discrepancies, which is consistent with known qualitative data analysis procedures. ${ }^{33}$

For the quantitative data, we used descriptive statistics (e.g., frequencies, means) to describe workshop participants' demographic characteristics. Process evaluation results are presented below for the HIV education workshops separate from the peer leader workshops and follow-up survey.

\section{Results}

HIV education workshops

Recruitment, reach, and context. All the intervention churches preferred to recruit workshop participants through existing ministries (i.e., organized groups such as choir, women's or men's groups, prayer group, bible study, social service or justice ministries) that were currently active in health-related matters. This recruitment approach resulted in four workshops at the Latino Catholic church ( $n=76$ participants). Three workshops were held at the Latino Pentecostal church ( $n=53$ participants). Only one combined workshop was held at the African American Baptist church due to the church leadership's preferences ( $n=19$ congregants). In terms of age trends, Latino Catholic participants were slightly younger compared to Latino Pentecostal and African American Baptist church participants (Table 1). Overall, more women than men participated in the workshops. Irrespective of denomination, a lower percentage of Latino participants 
Table 1. Demographic Characteristics of the HIV Education Workshop Participants

\begin{tabular}{lccc}
\hline & $\begin{array}{c}\text { Latino } \\
\text { Catholic } \\
(\boldsymbol{n}=\mathbf{7 6} \\
\text { participants) }\end{array}$ & $\begin{array}{c}\text { Latino } \\
\text { Pentecostal } \\
(\boldsymbol{n}=\mathbf{5 3} \\
\text { participants) }\end{array}$ & $\begin{array}{c}\text { African } \\
\text { American Baptist } \\
(\boldsymbol{n}=\mathbf{1 9} \text { participants })\end{array}$ \\
\hline Age, mean (range) & $38.8(17-73)$ & $40.8(19-72)$ & $46.2(34-74)$ \\
Tested for HIV, \% (n) & & \\
Yes & $55.3(42)$ & $39.6(21)$ & $57.9(11)$ \\
No & $36.8(28)$ & $56.6(30)$ & $21.1(4)$ \\
Missing & $7.9(6)$ & $3.8(2)$ & $21.1(4)$ \\
Held a leadership position in this & congregation, \% (n) \\
Yes & $26.3(20)$ & $43.4(23)$ & $68.4(13)$ \\
No & $61.9(47)$ & $50.9(27)$ & $10.5(2)$ \\
Missing & $11.8(9)$ & $5.7(3)$ & $21.1(4)$ \\
Sex, \% $(n)$ & \multicolumn{5}{|l}{} \\
Female & $55.3(42)$ & $60.4(32)$ & $57.9(11)$ \\
Male & $32.9(25)$ & $35.8(19)$ & $26.3(5)$ \\
Missing & $11.8(9)$ & $3.8(2)$ & $15.8(3)$ \\
\hline
\end{tabular}

reported having been tested for HIV or holding a church leadership position relative to the African American participants.

Implementation, dose-delivered, and fidelity. The first section of the HIV education workshop focused on basic facts about HIV and testing. Workshop facilitators were able to successfully convey key concepts around testing (e.g., how does an HIV test work, what kind of tests are there, and are test results confidential?), although the African American Baptist church session received a slightly lower score on this compared to the Latino sessions (Table 2). Most participants noted in their forms that the information on testing was helpful, and observed levels of enthusiasm varied across sessions from at least half looking interested to all. Of note, this section took longer to implement in the Latino congregations with an average of 36 min compared to the African American church with an average of $24 \mathrm{~min}$.

Following this section were "Frequently Asked Questions," meant to encourage participants to think critically and assess their own HIV knowledge. For example, the questions "What do people in your community think about people with HIV and AIDS?" and "What are some of the different ways that people in your community say that HIV is spread?" yielded different answers across racial/ethnic groups. Several Latino workshop participants shared community beliefs that HIV transmission occurred through blood transfusions, kissing, and sharing tooth brushes. Themes of isolation and discrimination against PLHIV were cited as prevalent among Latino participants as well as a fear of becoming infected through physical contact. In contrast, African American participants indicated limited community dialogue about HIV and that HIV was perceived as a "homosexual" disease. However, it is worth noting that there was no specific discourse on the phenomenon of "men on the down low" despite

Table 2. Fidelity by Church

\begin{tabular}{|c|c|c|c|c|c|c|}
\hline & \multicolumn{2}{|c|}{ Latino Catholic ${ }^{\mathrm{a}}$} & \multicolumn{2}{|c|}{ Latino Pentecostal ${ }^{\mathbf{b}}$} & \multicolumn{2}{|c|}{ African American Baptist ${ }^{c}$} \\
\hline & $\begin{array}{l}\text { Execution } \\
\text { mean }\end{array}$ & $\begin{array}{l}\text { Enthusiasm } \\
\text { mean }\end{array}$ & $\begin{array}{l}\text { Execution } \\
\text { mean }\end{array}$ & $\begin{array}{l}\text { Enthusiasm } \\
\text { mean }\end{array}$ & $\begin{array}{l}\text { Execution } \\
\text { mean }\end{array}$ & $\begin{array}{l}\text { Enthusiasm } \\
\text { mean }\end{array}$ \\
\hline \multicolumn{7}{|l|}{ Basic facts about HIV and HIV testing } \\
\hline $\begin{array}{l}\text { Key concepts included basic facts about how HIV is } \\
\text { transmitted, HIV prevalence in their community, and } \\
\text { importance of HIV testing }\end{array}$ & 4.2 & 3.5 & 4.3 & 4.0 & 3.0 & 4.0 \\
\hline \multicolumn{7}{|l|}{ Frequently asked questions about HIV } \\
\hline $\begin{array}{l}\text { Discussion related to "What do people in your community } \\
\text { think about people with HIV and AIDS?" and "What are some } \\
\text { of the different ways that people in your community say that } \\
\text { HIV is spread? }\end{array}$ & 4.2 & 2.7 & 3.3 & 3.6 & 5.0 & 4.0 \\
\hline \multicolumn{7}{|l|}{ Understanding HIV and stigma through video testimonials } \\
\hline $\begin{array}{l}\text { Key concepts included definition of stigma, the consequences } \\
\text { of stigma, and the role of the church in preventing } \\
\text { HIV-related stigma }\end{array}$ & 4.5 & 4.0 & 3.0 & 2.3 & 5.0 & 4.0 \\
\hline
\end{tabular}

${ }^{a}$ Score is the average of three HIV education workshops and three peer leader workshops, as well as one combined workshop (i.e., HIV education workshop was combined with peer leader workshop).

${ }^{\mathrm{b}} \mathrm{S}$ core is the average of three HIV education workshops and three peer leader workshops.

'Score based on a single combined workshop (i.e., HIV education workshop was combined with peer leader workshop).

Numbers indicate scores of:

$1-2=$ facilitator failed to convey key concepts/none or very few participants were interested/engaged.

$3=$ facilitator conveyed some of the key concepts/about half were interested/engaged.

4-5 = facilitator conveyed nearly all of the key concepts/all or nearly all participants were interested/engaged. 
the misperception that they are crucial agents of HIV transmission in the black community. ${ }^{34}$

The next section of the workshop used video testimonials to spark discussion and promote understanding about HIV and stigma. The Latino Pentecostal sessions received the lowest average scores for conveying key messages compared to Latino Catholic and African American sessions. The level of enthusiasm was also lower at the Latino Pentecostal church (Table 2). The observer noted that "there was a lot of victimization/victim blaming, and participants seemed to be having a tough time putting themselves in the shoes of PLHIV." For another workshop in this church, the observer noted that "the difference between the eagerness (of some participants) to speak up in the HIV Testing Activity and "Frequently Asked Questions," and the difficulty of getting people to talk during the stigma section, was definitely striking."

\section{Peer leader workshop and follow-up}

Recruitment, reach, and context. Because churches elected to implement the workshops with established ministry groups, the peer leaders tended to be very active members of the church and lay ministry leaders. They were trained during a single workshop, which was cofacilitated by members of the project team. Furthermore, this workshop provided information and practice on how to talk about HIV with fellow congregants and community members through a series of role-playing exercises, which used a motivational interviewing approach taught by the facilitators. Examples of skills were learning to use open-ended questions, reflective listening, and exploration of ambivalence about HIV testing and reasons for HIV stigma. A total of 56 adults participated in the peer leader workshops across the three intervention churches (Table 3). The mean age was mid-40s and over $80 \%$ were female. Peer leaders in the African American congregation reported having been tested for HIV (58\%) compared to Latinos in the Pentecostal (42\%) and Catholic (48\%) churches. Furthermore, over $65 \%$ of the peer leaders at the Latino Pentecostal and African American churches indicated they held a leadership position in their congregation.

Implementation, dose-delivered, and fidelity. Based on participant evaluation forms, over $80 \%$ of peer leaders thought the information was useful, engaging, and appropriate for the church environment. Observation data suggested high levels of interest and enthusiasm among peer leaders in all churches during the role-
Table 3. Demographic Characteristics of the Peer Leader Workshop Participants

\begin{tabular}{lccc}
\hline & $\begin{array}{c}\text { Latino } \\
\text { Catholic } \\
(\boldsymbol{n}=\mathbf{2 5} \\
\text { participants) }\end{array}$ & $\begin{array}{c}\text { Latino } \\
\text { Pentecostal } \\
(\boldsymbol{n}=\mathbf{1 2} \\
\text { participants) }\end{array}$ & $\begin{array}{c}\text { African } \\
\text { American Baptist } \\
(\boldsymbol{n}=19 \text { participants) }\end{array}$ \\
\hline Age, mean (range) & $42.4(29-73)$ & $42.9(29-54)$ & $46.2(34-74)$ \\
Ever tested for HIV, \% $(n)$ & & \\
Yes & $48(12)$ & $42(5)$ & $58(11)$ \\
No & $24(6)$ & $50(6)$ & $21(4)$ \\
Missing & $28(7)$ & $8(1)$ & $21(4)$ \\
Most recent HIV test, $\%(n)$ & & $26(5)$ \\
$<1$ year & $24(6)$ & $0(0)$ & $11(2)$ \\
1-2 years & $8(2)$ & $0(0)$ & $26(5)$ \\
$2+$ years & $12(3)$ & $42(5)$ & $21(4)$ \\
Never & $28(7)$ & $50(6)$ & $16(3)$ \\
Missing & $28(7)$ & $8(1)$ & $68(13)$ \\
Held a leadership position in this congregation, \% (n) & \\
Yes & $24(6)$ & $66(8)$ & $11(2)$ \\
No & $44(11)$ & $17(2)$ & $21(4)$ \\
Missing & $32(8)$ & $17(2)$ & $26(5)$ \\
Sex, \% (n) & & & $58(11)$ \\
Female & $28(7)$ & $92(11)$ & $0(0)$ \\
Male & $44(11)$ & $8(1)$ & \\
Missing & $28(7)$ & & \\
\hline
\end{tabular}

${ }^{\mathrm{a} C}$ Combined session with HIV education workshop.

playing scenarios. Engaging in this activity appeared to positively affect fidelity regarding key messages (e.g., regarding empathy, nonjudgmental attitudes when talking with others, consequences of HIV stigma).

Several differences in participant responses were also noted. For example, the first activity used a video entitled "La Cruz que Peza/The Heavy Cross," which is a short, animated, silent depiction of a man carrying a cross through the streets of his community as he faces rejection. ${ }^{35}$ The film sparked thoughtful reflections by Latino participants about PLHIV in their own lives. The observers reported this section was particularly effective in eliciting empathy for PLHIV at the Latino churches.

Another difference involved implementation of role plays. The purpose of this activity was to provide participants a way to practice or rehearse how they would react to a specific situation in real life, as well as put themselves "in the shoes" of someone else and to promote empathy toward PLHIV. Latino participants were less familiar with the idea of role playing than African American participants. Workshop facilitators took extra time to explain and demonstrate this activity to the Latino groups, resulting in an average of $41 \mathrm{~min}$ for these sessions at the Latino churches compared to $25 \mathrm{~min}$ at the African American church. This activity appeared to accomplish its aim since it sparked 
in-depth discussions about HIV-related stigma and HIV testing among Latino participants, including the myths or misconceptions about how the disease is transmitted in the Latino community.

Conducting the follow-up telephone survey with all of the peer leaders was difficult due to a lack of availability due to competing priorities (e.g., busy at work) and outdated contact information. Only 27 out of the 56 peer leaders were reached for the follow-up telephone survey. All of those contacted reported talking to someone about HIV testing after the workshop, and $74 \%$ reported talking with someone about HIVrelated stigma. Latino peer leaders reported speaking to up to 20 family members about HIV-related topics (range 1-20, median 5), whereas African American peer leaders reported speaking to up to 4 family members (range 1-4, median 1). A slightly greater proportion of African American peer leaders reported speaking with other congregants (55\%) compared to their Latino counterparts (50\%); however, a larger proportion of African American peer leaders (67\%) reported talking to clergy or religious leaders than Latino peer leaders $(28 \%)$.

\section{Discussion}

Our process evaluation highlights factors that affected implementation of a church-based HIV intervention across two disparity populations. Specifically, Latino participants at both intervention churches tended to have lower education than African American participants and recounted numerous HIV-related misconceptions in their communities, which required more time to address, and Latino participants also had less prior experience with role-playing exercises. Despite these disparities, the in-person, nonformal educational approach encouraged Latino congregants to disclose their own experiences with PLHIV, which created a valuable dialogue about the importance of empathy for PLHIV. The workshop seemed to create a "safe space" for discussions about HIV and HIV testing and the nonverbal animated video sparked numerous discussions about HIV-related stigma.

The peer leader model was generally well received by participants from both Latino intervention churches, possibly reflecting comfort with the community health promoter or promotora model that has been used extensively in Latin America and in the United States among Latino immigrant populations to address disparities. ${ }^{36}$ Most Latino peer leaders reported feeling comfortable speaking about HIV with people inside and outside the church. Latino peer leaders also reported speaking with up to 20 people within their social network about HIV-related stigma, particularly family members, which was a higher number compared to African American participants. These findings are consistent with another study that leveraged peer motivators in Latino communities to improve HIV education and testing. ${ }^{31}$ Additional research is needed on how to leverage the natural occurring social networks within Latino churches, particularly since social networks in general have been found to affect various health conditions through social support, access to resources, social engagement, and social norms. ${ }^{37}$ Furthermore, the fact that peer leaders in the Latino Pentecostal church held leadership positions has implications for such an approach, especially since leadership is highly promoted among congregants of this tradition. ${ }^{38,39}$

This process evaluation also revealed important lessons about implementation in the African American church. Intervention participants were engaged and enthusiastic during the workshops, which dovetails the positive findings regarding acceptability and feasibility from other HIV-related health promotion research situating health education programming within historically African American churches. ${ }^{40-46}$ Our study also found that the peer leader model generated a dialogue between peer leaders and members of their social networks, especially around the topic of HIV testing, and with clergy and other religious leaders. For reasons unknown to the research team, the pastor decided to restrict FAITH's educational component to a joint HIV education and peer leader session and only invited 20 lay leaders to participate, which resulted in less dose-received at the African American intervention church and thus a limitation of the study. However, because tailoring and community input are important for dissemination across diverse faith settings and to adhere to CBPR principles of partnership, we had to allow churches to determine the number of workshops offered at their church. This difference in number of FAITH workshops highlights important implementation issues in real-world settings. It also suggests the need for public health researchers to gain a deeper understanding of the role of organizational climate in historically black churches and its implications for program implementation. ${ }^{40}$ Given that black churches have historically been a refuge from outside forces of discrimination and oppression, it is not surprising that the need for trust and ongoing commitment from outside entities are crucial factors found by other researchers. ${ }^{2,47,48}$ Addressing HIV disparities, 
particularly as related to prevention programming, requires that public health researchers invest substantial time and effort in understanding how HIV prevention modalities within the church's tradition might differ from the social construction of HIV prevention from a public health perspective. ${ }^{49}$

This process evaluation highlights critical implementation factors that can help interpret the overall effectiveness findings, as well as issues that similar interventions implemented across race/ethnic groups may need to take into account. Nevertheless, we have limited ability to generalize to other settings given the potentially unique features of participants in the FAITH workshops. Another limitation is that the range of data collection methods used all have weaknesses such as self-report and observer bias, although triangulating these different data sources helps address these issues. ${ }^{50}$ Using in vivo observations (i.e., conducted with an observer present at the intervention session) as we did is thought to have the added advantage of being able to detect nonverbal forms of communication that could affect implementation. ${ }^{51}$ These types of observations are particularly well suited for understanding how the intervention was received (e.g., level of enthusiasm). ${ }^{51}$ However, there are multiple factors that could have affected implementation (e.g., facilitator's style) that were not assessed.

\section{Conclusion}

Our study examined implementation and fidelity across diverse faith settings and in doing so we contribute to new knowledge that may help future implementation efforts of evidence-based intervention programs in Latino and African American communities. ${ }^{2}$ Similar to other studies, we found that the concept of "seeds" or peer motivators was feasible and acceptable across faith settings. Future work should formally leverage and measure peer motivator's social networks inside and outside of church to form a powerful grid disseminating accurate information about HIV and fomenting empathy for PLHIV.

\section{Acknowledgments}

This study was supported by Grant Number 1 R01 HD050150 (Derose) from the Eunice Kennedy Shriver National Institute of Child Health and Human Development (NICHD)/National Institutes of Health (NIH). This research was also supported by Grant Number T32 HS00046 from the Agency for Healthcare Research and Quality (Payán). Its contents are solely the respon- sibility of the authors and do not necessarily represent the official views of the NICHD/NIH or AHRQ.

The authors acknowledge members of the research team (David E. Kanouse, Malcolm V. Williams, Jennifer Hawes-Dawson, Kartika Palar, Blanca Dominguez, and Alexandria Felton) and the study's Community Advisory Board (Rev. Michael A. Mata, Rev. Dr. Clyde W. Oden, Delis Alejandro, Father Chris Ponnet, and Richard Zaldivar). They also thank Deborah O. Collins, Kerry Brown, Carlos Campa, and Patricia Montes of the Long Beach Department of Health and Human Services for their contributions to the HIV education workshop and testing components.

\section{Authors Disclosure Statement}

No competing financial interests exist.

\section{References}

1. Centers for Disease Control and Prevention. HIV Surveillance Report, 2015. 2016. Available at https://www.cdc.gov/hiv/pdf/library/reports/ surveillance/cdc-hiv-surveillance-report-2015-vol-27.pdf Accessed July 26, 2017.

2. Sutton MY, Parks CP. HIV/AIDS prevention, faith, and spirituality among black/African American and Latino communities in the United States: strengthening scientific faith-based efforts to shift the course of the epidemic and reduce HIV-related health disparities. J Relig Health. 2013;52:514-530.

3. Centers for Disease Control and Prevention. HIV Surveillance Report. 2014. Available at https://www.cdc.gov/hiv/pdf/library/reports/surveillance/ cdc-hiv-surveillance-report-us.pdf Accessed July 26, 2017.

4. Espinoza L, Dominguez K, Romaguera R, et al. HIV/AIDS among Hispanics-United States, 2001-2005. MMWR Morb Mortal Wkly Rep. 2007;56:1052-1057.

5. Laurencin CT, Christensen DM, Taylor ED. HIV/AIDS and the AfricanAmerican community: a state of emergency. J Natl Med Assoc. 2008:100:35-43.

6. Flaskerud JH, Nyamathi AM, Uman GC. Longitudinal effects of an HIV testing and counseling programme for low-income Latina women. Ethn Health. 1997;2:89-103.

7. National AIDS Policy. National HIV/AIDS Strategy for the United States: updated to 2020. 2015. Available at https://www.hiv.gov/sites/default/ files/nhas-update.pdf Accessed July 26, 2017.

8. Nunn A, Cornwall A, Thomas G, et al. What's God got to do with it? Engaging African-American faith-based institutions in HIV prevention. Glob Public Health. 2013;8:258-269.

9. Seale JP, Fifield J, Davis-Smith YM, et al. Developing culturally congruent weight maintenance programs for African American church members. Ethn Health. 2013;18:152-167.

10. Pew Research Center. Religious Landscape Study. 2015. Available at http://www.pewforum.org/religious-landscape-study/racial-andethnic-composition/ Accessed July 26, 2017.

11. Campbell MK, Hudson MA, Resnicow K, et al. Church-based health promotion interventions: evidence and lessons learned. Annu Rev Public Health. 2007;28:213-234.

12. Tettey NS, Duran PA, Andersen HS, et al. "It's like backing up science with scripture": lessons learned from the implementation of HeartSmarts, a faith-based cardiovascular disease health education program. J Relig Health. 2016;55:1078-1088.

13. Tang TS, Nwankwo R, Whiten Y, et al. Outcomes of a church-based diabetes prevention program delivered by peers: a feasibility study. Diabetes Educ. 2014:40:223-230.

14. Leone LA, Allicock M, Pignone MP, et al. Cluster randomized trial of a church-based peer counselor and tailored newsletter intervention to promote colorectal cancer screening and physical activity among older African Americans. Health Educ Behav. 2016;43:568-576. 
15. Raja S, Teti M, Knauz R, et al. Implementing peer-based interventions in clinic-based settings: Lessons from a multi-site HIV prevention with positives initiative. J HIV AIDS Soc Serv. 2008;7:7-26.

16. Israel BA, Schulz AJ, Parker EA, et al. Review of community-based research: assessing partnership approaches to improve public health. Annu Rev Public Health. 1998;19:173-202.

17. Williams MV, Palar K, Derose KP. Congregation-based programs to address HIV/AIDS: elements of successful implementation. J Urban Health. 2011;88:517-532.

18. Palar K, Mendel P, Derose KP. The organization of HIV and other health activities within urban religious congregations. J Urban Health. 2013;90:922-933.

19. Werber $L$, Derose KP, Dominguez BX, et al. Religious congregations' collaborations: with whom do they work and what resources do they share in addressing HIV and other health issues? Health Educ Behav. 2012;39:777-788

20. Bluthenthal RN, Palar K, Mendel $P$, et al. Attitudes and beliefs related to HIV/AIDS in urban religious congregations: barriers and opportunities for HIV-related interventions. Soc Sci Med. 2012;74:1520-1527.

21. Derose KP, Mendel PJ, Kanouse DE, et al. Learning about urban congregations and HIV/AIDS: community-based foundations for developing congregational health interventions. J Urban Health. 2010;87: 617-630.

22. Derose KP, Mendel PJ, Palar K, et al. Religious congregations' involvement in HIV: a case study approach. AIDS Behav. 2011;15:1220-1232.

23. Pettigrew TF, Tropp LR. A meta-analytic test of intergroup contact theory. J Pers Soc Psychol. 2006;90:751-783.

24. Derose KP, Griffin BA, Kanouse DE, et al. Effects of a pilot church-based intervention to reduce HIV stigma and promote HIV testing among African Americans and Latinos. AIDS Behav. 2016;20:1692-1705.

25. Saunders RP, Evans MH, Joshi P. Developing a process-evaluation plan for assessing health promotion program implementation: a how-to guide. Health Promot Pract. 2005;6:134-147.

26. Yeary $\mathrm{KH}$, Klos LA, Linnan L. The examination of process evaluation use in church-based health interventions: a systematic review. Health Promot Pract. 2012;13:524-534.

27. Green LW. From research to "best practices" in other settings and populations. Am J Health Behav. 2001;25:165-178.

28. Green LW, Stoto MA. Linking research and public health practice: a vision for health promotion and disease prevention research. Am J Prev Med. 1997;13(6 Suppl):5-8.

29. Glasgow RE, Vogt TM, Boles SM. Evaluating the public health impact of health promotion interventions: the RE-AIM framework. Am J Public Health. 1999;89:1322-1327

30. Derose KP, Bogart LM, Kanouse DE, et al. An intervention to reduce HIVrelated stigma in partnership with African American and Latino churches. AIDS Educ Prev. 2014;26:28-42.

31. Ramos RL, Ferreira-Pinto JB, Rusch ML, et al. Pasa la voz (spread the word): using women's social networks for HIV education and testing. Public Health Rep. 2010;125:528-533.

32. Dedoose [computer program]. Version 6.1.182015. Available at http://www.dedoose.com/.

33. Miles M, Huberman A. Qualitative Data Analysis: An Expanded Sourcebook 2nd ed. Thousand Oaks, CA: Sage Publications, Inc., 1994.

34. Bond $L$, Wheeler DP, Millett GA, et al. Black men who have sex with men and the association of down-low identity with HIV risk behavior. Am J Public Health. 2009;99 Suppl 1:S92-S95.

35. Logo K. La Cruz Que + Pesa. 2011.

36. Haughton J, Ayala GX, Burke $\mathrm{KH}$, et al. Community health workers promoting physical activity: targeting multiple levels of the social ecological model. J Ambul Care Manage. 2015;38:309-320.

37. Smith KP, Christakis NA. Social networks and health. Annu Rev Sociol. 2008;34:405-429.
38. Schiffman M. Hispanic Pentecostal Beliefs. Opposing Views 2014.

39. Alvarez CE. Hispanic pentecostals: Azusa street and beyond. Encounter. 2002;63:1-10.

40. Stewart JM. A developing framework for the development, implementation and maintenance of HIV interventions in the African American church. J Health Care Poor Underserved. 2015;26:211-222.

41. Rao D, Desmond M, Andrasik M, et al. Feasibility, Acceptability, and preliminary efficacy of the unity workshop: an internalized stigma reduction intervention for African American women living with HIV. AIDS Patient Care STDS. 2012;26:614-620.

42. Pichon LC, Powell TW. Review of HIV testing efforts in historically black churches. Int J Environ Res Public Health. 2015;12:6016-6026.

43. Berkley-Patton JY, Moore E, Berman M, et al. Assessment of HIV-related stigma in a US faith-based HIV education and testing intervention. J Int AIDS Soc. 2013;16(3 Suppl 2):18644.

44. Berkley-Patton JY, Hawes S, Moore E, et al. Examining facilitators and barriers to HIV testing in African American churches using a communitybased participatory research approach. Ann Behav Med. 2012;43: S277-S277.

45. Berkley-Patton J, Thompson CB, Moore E, et al. An HIV testing intervention in African American churches: pilot study findings. Ann Behav Med. 2016.

46. Berkley-Patton J, Bowe-Thompson C, Bradley-Ewing A, et al. Taking It to the Pews: a CBPR-guided HIV awareness and screening project with black churches. AIDS Educ Prev. 2010;22:218-237.

47. Galiatsatos $P$, Hale WD. Promoting health and wellness in congregations through lay health educators: A case study of two churches. J Relig Health. 2016;55:288-295

48. Odulana A, Kim MM, Green M, et al. Participating in research: attitudes within the African American church. J Relig Health. 2014;53: 373-381.

49. Isler MR, Eng E, Maman S, et al. Public health and church-based constructions of HIV prevention: black Baptist perspective. Health Educ Res. 2014:29:470-484.

50. Windsor RA. Evaluation of Health Promotion and Disease Prevention Programs. 5th ed. New York: Oxford University Press, 2015.

51. Breitenstein SM, Gross D, Garvey CA, et al. Implementation fidelity in community-based interventions. Res Nurs Health. 2010;33:164-173.

Cite this article as: Flórez KR, Payán DD, Derose KP, Aunon F, Bogart LM (2017) Process evaluation of a peer-driven, HIV stigma reduction and HIV testing intervention in Latino and African American churches, Health Equity 1:1, 109-117, DOI: 10.1089/heq.2017.0009.

\section{Abbreviations Used}

$\mathrm{CBPR}=$ community-based participatory research

FAITH = Facilitating Awareness to Increase Testing for HIV PLHIV = people living with HIV

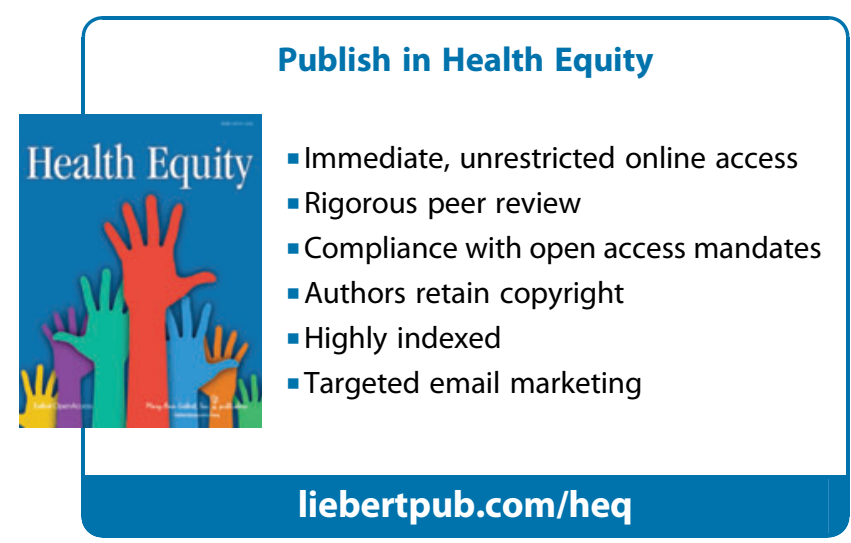

